\title{
Influence of twin and multi-rig trawl systems on CPUE in the Danish Norway lobster (Nephrops norvegicus) fishery
}

\author{
Feekings, Jordan P.; Berg, Casper Willestofte; Krag, Ludvig Ahm; Eigaard, Ole Ritzau
}

Published in:

Fisheries Research

Link to article, DOI:

10.1016/j.fishres.2015.11.017

Publication date:

2016

Document Version

Publisher's PDF, also known as Version of record

Link back to DTU Orbit

Citation (APA):

Feekings, J. P., Berg, C. W., Krag, L. A., \& Eigaard, O. R. (2016). Influence of twin and multi-rig trawl systems on CPUE in the Danish Norway lobster (Nephrops norvegicus) fishery. Fisheries Research, 175, 51-56. https://doi.org/10.1016/j.fishres.2015.11.017

\section{General rights}

Copyright and moral rights for the publications made accessible in the public portal are retained by the authors and/or other copyright owners and it is a condition of accessing publications that users recognise and abide by the legal requirements associated with these rights.

- Users may download and print one copy of any publication from the public portal for the purpose of private study or research.

- You may not further distribute the material or use it for any profit-making activity or commercial gain

- You may freely distribute the URL identifying the publication in the public portal 


\title{
Influence of twin and multi-rig trawl systems on CPUE in the Danish Norway lobster (Nephrops norvegicus) fishery
}

\author{
Jordan Feekings $^{\mathrm{a}, *}$, Casper Willestofte Berg ${ }^{\mathrm{b}}$, Ludvig Ahm Krag ${ }^{\mathrm{a}}$, Ole Ritzau Eigaard ${ }^{\mathrm{b}}$ \\ a Technical University of Denmark, National Institute of Aquatic Resources, North Sea Science Park, PO Box 101, DK-9850, Hirtshals, Denmark \\ b Technical University of Denmark, National Institute of Aquatic Resources, Charlottenlund Slot-Jægersborg Allé 1, DK-2920, Charlottenlund, Denmark
}

\section{A R T I C L E I N F O}

\section{Article history:}

Received 11 August 2014

Received in revised form

20 November 2015

Accepted 22 November 2015

\section{Keywords:}

Trawl

Twin trawl

Multi-rig trawl

Norway lobster

Nephrops norvegicus

Cod

Plaice

Haddock

Selectivity

Catch rates

CPUE

\begin{abstract}
A B S T R A C T
One of the most effective ways to alter catch and length compositions in trawls is to adjust the mesh size or add selective devices such as sorting grids and selective netting panels. These changes are often introduced into the fishery in a top down manner whereby fishermen are forced to comply with specific legislation. However, fishermen have also introduced gear modifications that have contributed to improving species selectivity in trawls. One of the simplest and most effective modifications that came from industry was the development and introduction of twin and multi-rig trawls. Here we analyse catch rates of four target species, Norway lobster (Nephrops norvegicus), cod (Gadus morhua), plaice (Pleuronectes platessa) and haddock (Melanogrammus aeglefinus), to try and understand how the use of multi-rig trawls have altered catch rates within the Danish demersal trawl fishery over the last 16 years (1997-2012). Results showed that catch rates of Nephrops in multi-rig trawls were significantly higher (1.89-2.03) than those in single trawls. For cod, haddock and plaice there was no significant effect of gear type. The results are discussed in relation to the Common Fisheries Policy reform and the increasing importance of industry introduced gear modifications.
\end{abstract}

() 2015 Elsevier B.V. All rights reserved.

\section{Introduction}

Over the last 30 years there has been a shift in bottom trawl fisheries, whereby fishermen traditionally trawling with single trawls have shifted to using two or more trawls rigged together and towed simultaneously. Twin trawls were initially developed by two industry/research projects using the flume tank in Hirtshals, Denmark around 1984 . Their uptake by the industry was relatively quick, and it did not take long before the majority of the fishing vessels in Northern Jutland changed over to using twin trawls. It took a little longer for Swedish fishermen to discover the benefits; they were probably afraid that the difficult trawling conditions with a lot of skerries and islands made it cumbersome to use two nets, because a lot of turning was needed. The uptake of twin trawls by Swedish fishermen occurred around 1989-92 (Eggert and Ulmestrand, 2000) when the value of Norway lobster (Nephrops norvegicus) started increasing. Since then, the use

\footnotetext{
* Corresponding author.

E-mail address: jpfe@aqua.dtu.dk (J. Feekings).
}

of twin trawls has increased and in 2012 the majority of the Danish demersal fleet fishing in the Skagerrak and Kattegat use such gear. This shift in trawl design coincided with a general shift in primary target species, from cod (Gadus morhua) and other gadoid species to Norway lobster. Demersal fishermen are now targeting Norway lobster more than cod due to the reduced size of the cod populations (Fig. 1; http://www.statistikbanken.dk).

Twin and multi-rig trawls are towed by a single boat and generally consist of two or more smaller trawl nets, of similar design, rigged together (Sangster and Breen, 1998). This type of rigging was developed to enable an increase in the horizontal fishing area covered by the ground gear without increasing the vertical opening and towing resistance, and hence a greater catch efficiency for certain demersal species can be achieved by the same towing power (Sainsbury, 1996; Eigaard et al., 2011). The highest efficiency increase is achieved for species closely associated to the bottom which are not necessarily herded by the sweeps, and due to their sedentary behavior are not likely to escape over the headline of the trawl. Species such as Norway lobster and monkfish (Lophius spp.) fall into this category (Sangster and Breen, 1998; Eigaard et al., 2011). For species that are prone to herding by the doors 
and sweeps, the area swept by the total gear (door spread) will determine the catch. This is the case for species such as plaice (Pleuronectes platessa), haddock (Melanogrammus aeglefinus) and cod (Eigaard et al., 2011). Hence, if the swept area of the ground gear is doubled, when shifting from e.g., a single-rig cod trawl to a twin-rig Nephrops trawl one can in theory expect catches of Norway lobster to double, and similar when doubling the herding area (door spread) for more active species (Fig. 2). Furthermore, twin and multi-rig trawls typically have a lower headline height when compared to most single rig trawls. This side-effect can reduce the catching efficiency for some species (e.g., haddock and whiting (Merlangius merlangus) which avoid capture by actively swimming over the headline (Main and Sangster, 1981). Sangster and Breen, 1998 found the twin trawl significantly out-fished the single trawl for haddock, plaice, lemon sole (Microstomus kitt), anglerfish (Lophius piscatorius), and Norway lobster; even when correcting for the total area swept by the two gears (door spread), and also when correcting only for the area swept by the ground gear. In addition, landings per unit effort (LPUE) of Norway lobster in the Swedish demersal fishery were found to be 1.7 times greater for twin trawls compared to single trawls (Eggert and Ulmestrand, 2000).

Previous studies have shown that the herding effect of the otterboards and sweeps do not affect the capture process for Norway Lobster (Main and Sangster, 1985; Thorsteinsson, 1986; Newland and Chapman, 1989), while on the contrary, affects most commercially targeted fish species (Wardle, 1993). Norway lobsters' swimming escape reaction (tail flips) commonly occurs either on direct contact or shortly before contact with the fishing gear, which generally lifts the individuals into the trawl (Main and Sangster,
1985; Thorsteinsson, 1986; Newland and Chapman, 1989). Escape behavior from within the trawl generally consists of a series of tail flips. Consequently the majority of the selection process takes place along the lower panel of the entire trawl (Cole and Simpson, 1965; Hillis and Earley, 1982; Robertson and Ferro, 1991; Briggs, 1992; Frandsen et al., 2010), where the process is more representative of a passive sieving process.

In Denmark, throughout the study period Norway lobster has been caught primarily using trawls fishing with a mesh size of 70-90 $\mathrm{mm}$. In the Kattegat, cod has historically been the main target species (Feekings et al., 2012). However, as a result of the struggling cod stocks in the Kattegat and Skagerrak, a shift in target species has occurred and in 2012 Norway lobster accounted for approximately 73 and $22 \%$ of the total value of Danish demersal catches in the Kattegat and Skagerrak, respectively (Fig. 1; http://www. statistikbanken.dk). This shift in target species coincided with fishermen modifying their trawls to be directed towards Norway lobster. These modifications were typically aimed at increasing the area swept by the ground gear and thus increasing the catch efficiency for Norway lobster, and were obtained through (a) moving from single-rigged trawls to twin and multi-rigged trawls and (b) moving from trawl designs which focus on both horizontal and vertical net-opening (fish-trawls) to trawl designs with a focus on obtaining as much ground gear width as possible.

The use of twin and multi-rig trawls has dramatically increased over the last 30 years within the Danish demersal fleet and in general, most Northeast Atlantic demersal fisheries. There are indications from other European waters that catches of certain groundfish species increase when fishing with twin trawls as

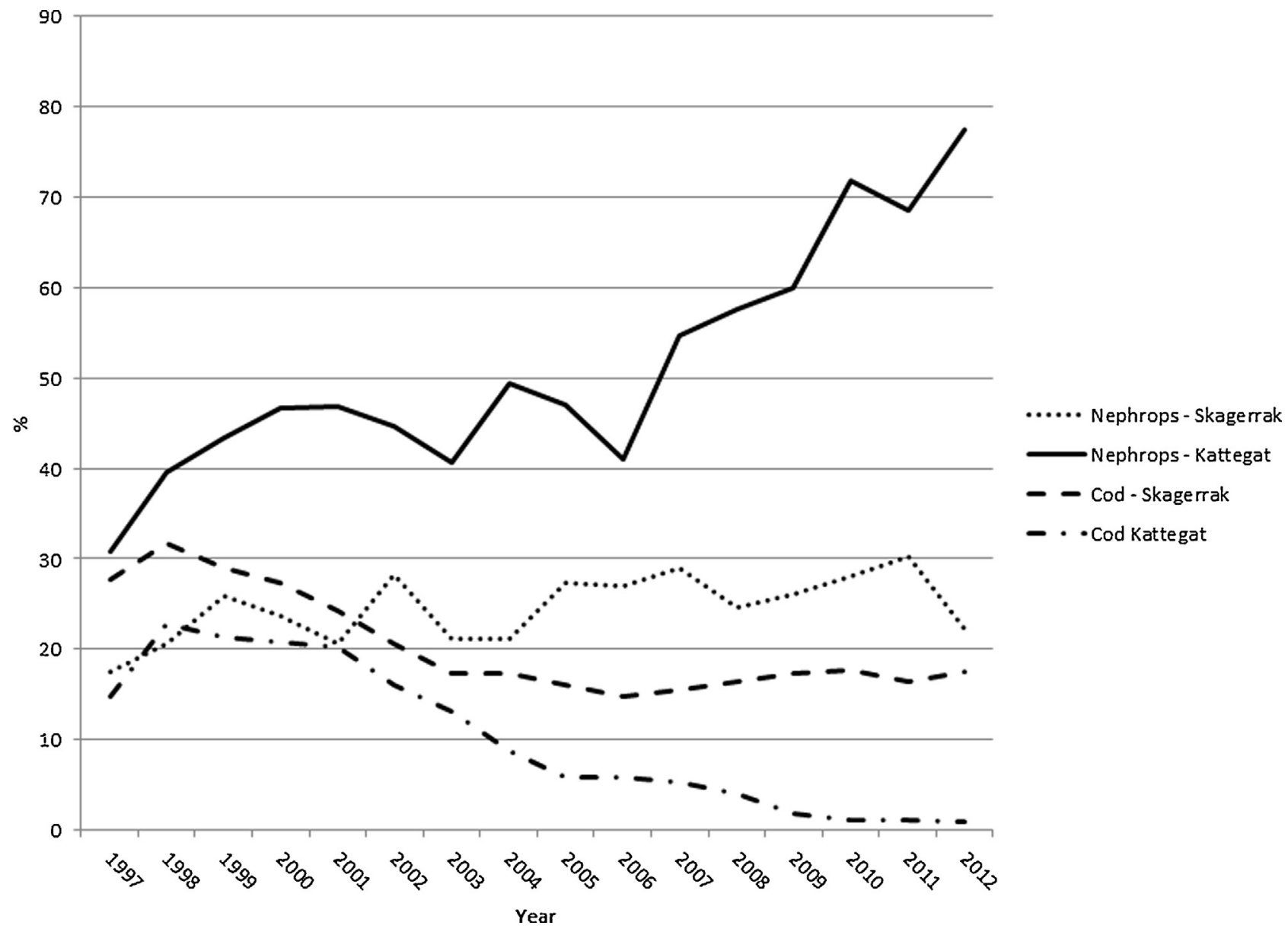

Fig. 1. Landings (in value (Danish Kroner)) by Danish vessels fishing in the Skagerrak and Kattegat during the period 1997-2012. 


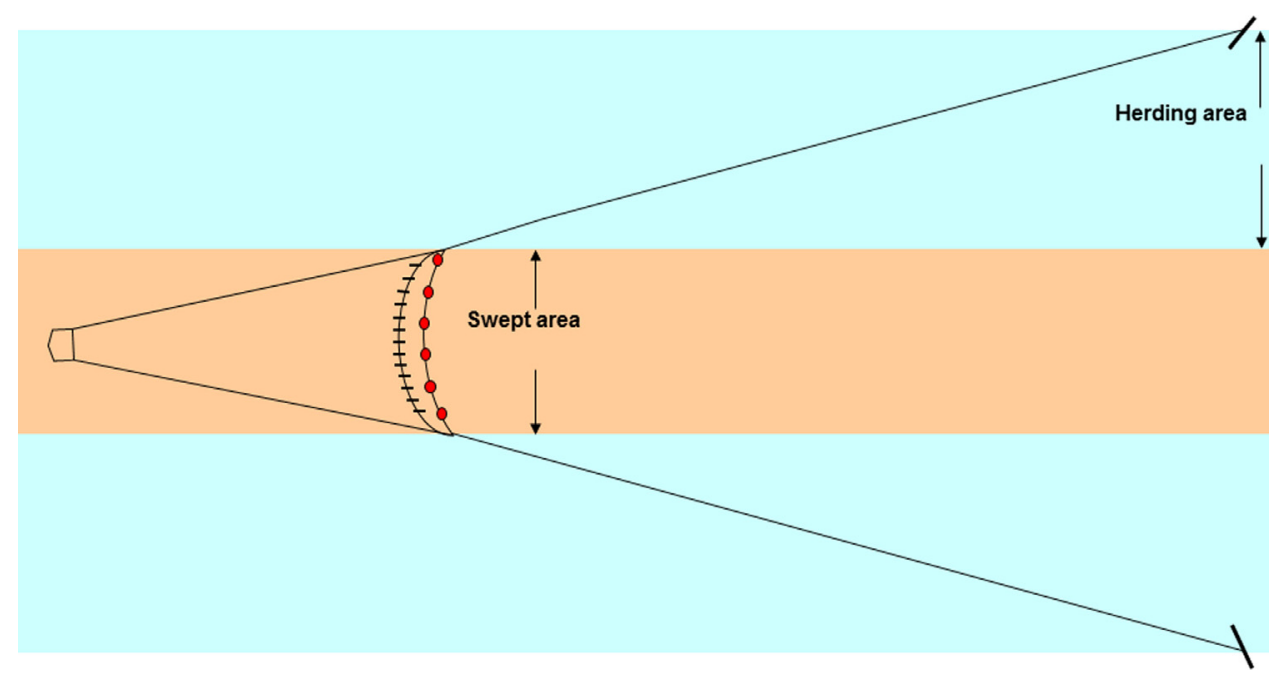

Fig. 2. Defines what are the herded and swept areas of a demersal trawl.

Table 1

Model components and their functions in describing catch rates (CPUE).

\begin{tabular}{|c|c|c|}
\hline Model components & Variable name & Description \\
\hline Gear & $\operatorname{gear}(i)$ & Effect of gear type (single and twin) on catch rates (CPUE). \\
\hline Time of year & $f_{3}\left(t_{2 i}\right)$ & Capture the seasonal effect in catches that occur due to variability in species' environmental preferences. \\
\hline Longitude, Latitude & $f_{1}\left(\operatorname{lon}_{i}\right.$, lat $\left._{i}\right)$ & Capture the spatial variability in catches that occurs due to species' environmental preferences. \\
\hline Vessel power & $\beta_{2} k W(i)$ & Larger vessels have the potential to tow larger nets, subsequently catching more fish. \\
\hline Year & $f_{2}\left(t_{i}\right)$ & Incorporates the differences in species abundances (i.e., captures annual variations in recruitment). \\
\hline Haul duration & $\beta_{1} \log \left(\right.$ duration $\left._{i}\right)$ & The longer the haul, the larger the catch. \\
\hline Vessel & $U(i)_{\text {vessel2 }} \sim N\left(0, \sigma_{\mathrm{u}}\right)$ & $\begin{array}{l}\text { Accounts differences in catch rates which can be vessel specific (e.g., the skipper effect, vessel type, changes in } \\
\text { management etc.). }\end{array}$ \\
\hline
\end{tabular}

opposed to single trawls (Sangster \& Breen, 1998). However, these results were obtained under experimental conditions. Here, we utilize at-sea-observer data collected on-board commercial vessels under commercial fishing practices to model CPUE of four major target species, Norway lobster, cod, plaice and haddock. The main objective is to elucidate whether CPUEs within the Danish demersal fleet have altered due to the move from single to twin and multi-rig trawls. The results are discussed in relation to experimental results and theory on target species behavior during the trawl capture process and in relation to the Common Fisheries Policy (CFP) reform and the increasing importance of gear modifications.

\section{Methods}

\subsection{Discard data}

Denmark has been collecting information on discards as part of an at-sea scientific observer program since the mid-1990s, with the aim of sampling all species from all demersal fisheries except the ones with minimal fishing effort and discards (Feekings et al., 2012). Information on the sampling strategy and data collection methods has previously been described by Feekings et al. (2012). In total, 2996 discard observer hauls took place in the Nephrops directed demersal trawl fishery over the period 1997-2012 (1496 in the Skagerrak (ICES area 3AN) and 1500 in the Kattegat (ICES area 3AS); Fig. 3). Due to the coarseness of the data, gears were classified into either single trawls or twin/multi-rig trawls (herein referred to as multi-rig trawls) and not further into the specific number of trawls used. All hauls used in the analysis had a mesh size between 70 and $90 \mathrm{~mm}$ and were defined as targeting Norway lobster in the database, irrespective of whether Norway lobster were caught or not.

\subsection{Statistical analysis}

The dataset is unbalanced, so we needed to include all nuisance factors that might affect the catch rate other than the gear type in order to get a correct estimate of the gear effect. All nuisance factors and the reasons for their inclusion are listed in Table 1. Some (16) missing $\mathrm{kW}$ data points were set to the mean of all the other data points.

Candidate blocking variables include vessel, haul, and trip, however a trip is mostly comprised of one or two hauls, so only the vessel is considered. In addition, many vessels have only performed a few hauls, which would lead to many random effects and potentially identifiability problems (given that some vessels only have zero catch hauls of some species). To reduce the computational complexity and help ensure identifiability, a pooled vessel identifier, where at least 5 hauls were required, was created. Some vessels have taken hauls using both gear types, which ensures that the gear effect can be separated from vessel effects.

We choose to model each species separately, and for each species we consider three models, one for the responses catch number $(\mathrm{Cn})$ and two for catch weight $(\mathrm{Cw}) . \mathrm{Cn}$ is count data

Table 2

Summary of discard data collected on-board demersal trawls targeting Norway lobster during the period 1997-2012.

\begin{tabular}{lll}
\hline & Single trawl & Twin trawl \\
\hline No. of trips & 50 & 369 \\
No. of hauls & 73 & 666 \\
No. of vessels & 16 & 71 \\
Vessel size $(\mathrm{kW}$ range) & $108-856$ & $100-1000$ \\
Haul duration $(\mathrm{h})$ & $5.5(1.7)$ & $6.2(1.6)$ \\
Total catch weight $(\mathrm{kg})$ & $368.0(211.3)$ & $675.2(420.0)$ \\
\hline
\end{tabular}

Standard deviations are in parenthesis. 


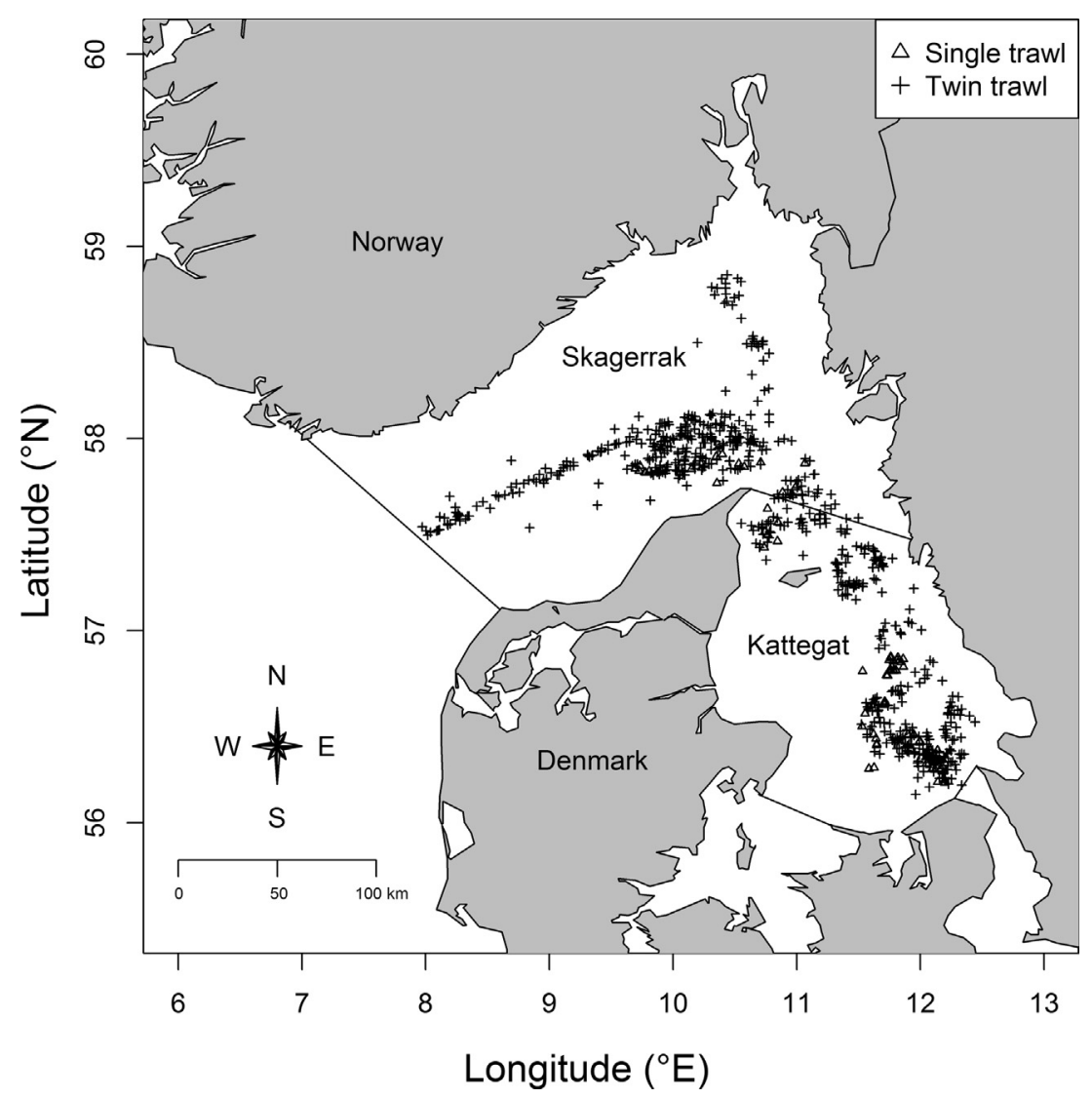

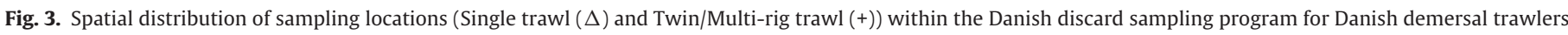
targeting Norway lobster during the period 1997-2012.

with a big spread in values, so we choose a negative binomial model here. Cw is continuous and non-negative, so we use DeltaLognormal model and a Tweedie (Tweedie, 1984) model for these. The Delta-Lognormal model consists of two independent submodels: one for presence/absence data and one for the strictly positive responses. For all models (negative binomial, Tweedie, and binomial + lognormal) the same mean value structure was used:

$$
\begin{aligned}
g\left(\mu_{i}\right)= & \operatorname{gear}(i)+\beta_{1} \log \left(\text { duration }_{i}\right)+\beta_{2} k W(i)+U(i)_{\text {vessel2 }} \\
& +f_{1}\left(\operatorname{lon}_{i}, \text { lat }_{i}\right)+f_{2}\left(t_{i}\right)+f_{3}\left(t_{2 i}\right)
\end{aligned}
$$

where gear ( $i$ ) maps the $i$ th haul to a categorical effect for each gear type, the $\beta \mathrm{s}$ are ordinary regression parameters, $U(i)_{\text {vessel } 2} \sim N\left(0, \sigma_{\mathrm{u}}\right)$ is a random effect for the vessel associated with haul $i, f_{1}$ is a 2-dimensional thin plate regression spline on the geographical coordinates, $f_{2}$ is a 1-dimensional thin plate spline for the effect of year (e.g., differences in species abundances), and $f_{3}$ is a cyclic cubic regression spline on the time of year (i.e., with same start end point) for capturing seasonal patterns. The function $g$ is the link function, which is taken to be the logit function for the binomial model, and the logarithm for the negative binomial model. The lognormal part of the delta-lognormal model is fitted by log-transforming the response and using the Gaussian distribution with a unit link. Each combination of quarter and age group (year) are estimated separately. While a 3D-smoother might be considered to model space-time interactions, these were not considered due to the extra computational costs. Smoothness selection was carried out with the restricted maximum likelihood (REML) method (Wood, 2011), and the double penalty approach to shrinkage smoothing was used (Giampiero and Wood, 2011) to ensure that insignificant effects could be completely eliminated from the model. The maximum basis dimension of each spline was chosen such the approximately one third of the effective degrees of freedom were used for the negative binomial model, and one tenth for the delta-lognormal and Tweedie models. A smaller value was chosen for the negative binomial model to ensure moderate computation times, although the results were nearly identical for any value above the one chosen.

\section{Results}

A total of 419 trips and 739 hauls from 85 vessels were included in the analysis (Table 2). Each haul had an average duration of approximately $6 \mathrm{~h}$. Mean total catch weights were considerably higher for multi-rig trawl than single trawls, with mean catch weights for the two gears being 675 and $368 \mathrm{~kg}$, respectively.

Multi-rig trawls were found to have significantly higher (positive) CPUE of Norway lobster; 1.89 (Tweedie model) and 2.03 (Negative binomial model) times higher (Fig. 4, Table 3). For cod, haddock and plaice, no significant effect of gear type was observed. The results for cod and plaice, while not significant, were lower in multi-rig trawls. For cod, the average catch rates were 9\% (Negbin) and $4 \%$ (Tweedie) lower in multi-rig trawls. CPUE of plaice were on average $32 \%$ (Negbin) and $2 \%$ (Tweedie) lower in multi-rig trawls. The results obtained herein for haddock, while also not significant, were found to be greater in multi-rig trawls, on average 26\% (Tweedie model) and 54\% (Negative binomial model) higher.

The final models explained between 23 and $79 \%$ of the deviance (Table 3). Visual inspection of the model residuals revealed no violation from any of the model assumptions (i.e., normality and homogeneity of variance). Results for the nuisance factors, haul duration, time, time of year, vessel power, vessel, and a spatial term are presented in Supplementary material (Table S1). 


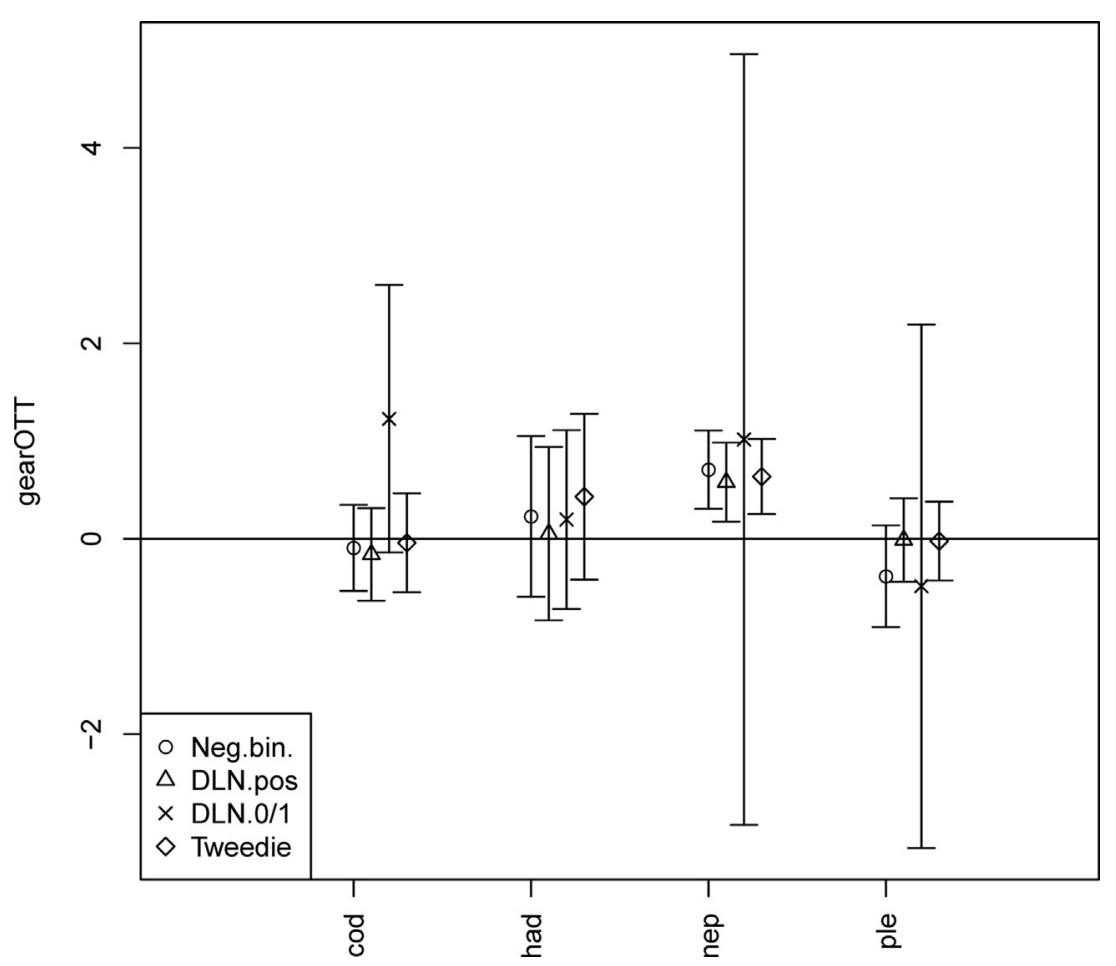

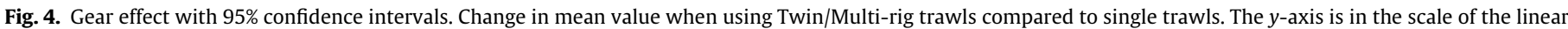

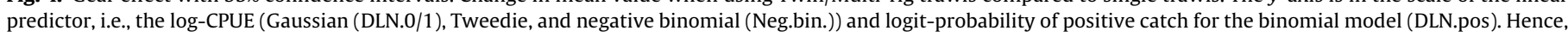

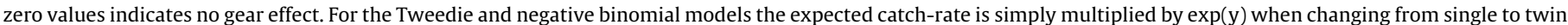
trawl, everything else being equal.

\section{Discussion}

Multi-rig trawls were found to have a CPUE for Norway lobster approximately 1.9 times what was observed for single trawls. This result supports what has previously been observed in the Swedish demersal trawl fishery, where the landings per unit effort ratio between twin and single trawls was found to be around 1.7 (Eggert and Ulmestrand, 2000). Furthermore, commercial fishing trials carried out in Scottish waters found that twin trawls caught around 340 per cent more Norway lobster than single trawls (Sangster and Breen, 1998). However, the extremely large difference was believed to be partially due to differences in ground gear shape between the two gears. These results are rather unexpected. One would expect a more modest increase in catches rates roughly equivalent to the difference in total ground gear width between the two gears. In our meta-analysis, the estimated 90\% increase in Norway lobster CPUE for multi-rig trawl is probably a result of additional trawl design developments (e.g., increased wing spread, twine materials) coinciding with their introduction, thus enabling a substantial increase (approx. a doubling) in ground gear width. Technological developments introduced throughout the investigated period (e.g., more efficient engines and electronic equipment) may of course also have contributed to the estimated increase (Eigaard et al., 2014).

Sangster and Breen (1998) also observed catch rates of plaice and lemon sole to be significantly higher (40\%) in twin trawls compared to single trawls. Herein, we observed no significant differences among the two gears for plaice. The reason Sangster and Breen (1998) observed an increase in catch rates of plaice and lemon sole was believed to be due to the increased bridle herding efficiency of the twin trawl used, which had the smaller angle

Table 3

Final model results. Asterisks denote significant difference at the 0.05 level.

\begin{tabular}{|c|c|c|c|c|c|c|}
\hline Species & Model & Estimate & Lower & Upper & $P$ value & DEV.EXPL(\%) \\
\hline Norway & Negbin & 2.03 & 1.36 & 3.00 & $<0.001^{*}$ & 29.8 \\
\hline lob- & Tweedie & 1.89 & 1.29 & 2.78 & $<0.001^{*}$ & 46.6 \\
\hline \multirow[t]{2}{*}{ ster } & Delta-Lognormal (gaussian) & & & & $0.004^{*}$ & 33.5 \\
\hline & Delta-Lognormal (binomial) & & & & 0.61 & 48.4 \\
\hline \multirow[t]{4}{*}{ Cod } & Negbin & 0.91 & 0.59 & 1.41 & 0.67 & 27.3 \\
\hline & Tweedie & 0.96 & 0.58 & 1.59 & 0.87 & 61.0 \\
\hline & Delta-Lognormal (gaussian) & & & & 0.50 & 54.5 \\
\hline & Delta-Lognormal (binomial) & & & & 0.07 & 22.8 \\
\hline \multirow[t]{4}{*}{ Haddock } & Negbin & 1.26 & 0.55 & 2.87 & 0.58 & 38.8 \\
\hline & Tweedie & 1.54 & 0.66 & 3.60 & 0.31 & 79.0 \\
\hline & Delta-Lognormal (gaussian) & & & & 0.91 & 49.9 \\
\hline & Delta-Lognormal (binomial) & & & & 0.67 & 38.5 \\
\hline \multirow[t]{4}{*}{ Plaice } & Negbin & 0.68 & 0.40 & 1.15 & 0.14 & 54.3 \\
\hline & Tweedie & 0.98 & 0.65 & 1.46 & 0.91 & 69.0 \\
\hline & Delta-Lognormal (gaussian) & & & & 0.95 & 63.9 \\
\hline & Delta-Lognormal (binomial) & & & & 0.72 & 53.7 \\
\hline
\end{tabular}


of attack. This adds some explanation to why contradictory results were observed herein. They also found catch rates of haddock in twin trawls to be significantly higher $(\sim 22 \%)$ than in single trawls. While the results obtained herein for haddock were not significant, the estimated catch rates were higher ( 40-60\%) for multi-rig trawls. The results obtained for cod showed no significant differences between the two gears, which coincides with what was observed in the Scottish experiment (Sangster and Breen, 1998). It should be noted that the comparisons between our results and those of Sangster and Breen (1998) should be handled with caution due to the different methods used.

The results for fish indicate that the herding area in a multi trawl rigging, determined by the sweep lengths, is not doubled, as it is for the ground gear. Based on the importance of Norway lobster in the Kattegat (73\% in value), shortening the sweeps makes sense as fish are of little importance. Unfortunately, detailed information on gear parameters (e.g., sweep lengths) was lacking. If such data were available it would allow for more detailed analysis on the effects of different gear parameters (e.g., sweep lengths) on catch compositions and how fishermen aim to optimize their Norway lobster fishery in a mixed fishery setting. Hence, collection of these data could provide valuable information on gear based species selectivity, and could be collected cost effectively as part of data collection programmes.

The move from single to twin/multi-rig trawls was industry initiated and occurred due to dwindling fish stocks and to fishermen realizing that they could obtain higher catch rates of crustaceans, such as Norway lobster and Northern shrimp (Pandalus borealis). With the reform of the European Union CFP, whereby a catch quota management system together with a discard ban (landing obligation) are to be introduced, gear selectivity modifications will come more into focus, especially those that come from a bottom up approach rather that the traditional top down system, thereby showing fishermen's ingenuity and ability to alter catch compositions to suit available quota. Under the new CFP, once a species quota is fished a vessel will be obligated to stop fishing, that is if no more quota can be sourced. To prevent this from occurring, a vessel can either alter its spatial and temporal fishing pattern in order to catch a different species composition, one that matches the available quota, or alter the selectivity of the gear. The move to twin trawling is a good example of industry driven selectivity changes that can have potential benefits under the new CFP. If fishermen have the freedom to modify their gear to obtain catch compositions that match their species quotas, the implementation of the reformed CFP will be more successful.

We observed a significant increase in the catch rates of Nephrops in twin/multi-rig trawls when compared to single trawls. For the three fish species studied, no significant effect of gear type was found. This indicates that the main difference between single and twin/multi-rig trawls is not the number of trawls used, rather the ratio between the swept (ground gear) and herded areas (sweeps; Fig. 2). Therefore, under a landings obligation, twin and multi-rig trawls, or more specifically the ratio between the swept area and the herded area, will be an effective tool to alter the species composition. A general problem for Norway lobster fishermen will most likely be to catch their Norway lobster quota before exhausting the vessels fish quotas. Maximizing the area swept by the netting in the trawls' catching zone and minimizing the sweep lengths will minimize the catch of fish in the demersal fishery. Such development is seen in the Norway lobster directed fleet in the North East Atlantic as more vessels are experimenting with multi-rig trawl systems consisting of 4-12 smaller trawls. Although catch rates for roundfish were not significantly different in twin/multi-rig trawls, the increased CPUE of Norway lobster indirectly leads to a reduction in the effort required to catch the quota of Norway lobster, and hence lower roundfish catches and fuel usage.

\section{Acknowledgements}

We would like to thank the at-sea observers for their hard work and dedication in collecting the data, the fishermen and the Danish Fishermen's Association for their collaboration. This project was financed by two separate projects (Bærekraftig sjøkrepsfiske and Bæredygtigt rejefiskeri I Skagerrak) under the European Regional Development Funds (ERDF) Interreg IVA programme.

\section{Appendix A. Supplementary data}

Supplementary data associated with this article can be found, in the online version, at http://dx.doi.org/10.1016/j.fishres.2015.11. 017.

\section{References}

Briggs, R.P., 1992. An assessment of nets with a square mesh panel as a whiting conservation tool in the Irish Sea Nephrops fishery. Fish. Res. 13, 133-152.

Cole, H.A., Simpson, A.C., 1965. Selection by trawl nets in the Nephrops fishery. Rapp. P.V. Reun. ICES 156, 203-205.

Eggert, H., Ulmestrand, M., 2000. A bioeconomic analysis of the Swedish Fishery for Norway Lobster (Nephrops norvegicus). Mar. Resour. Econ. 14, 225-244.

Eigaard, O.R., Rihan, D., Graham, N., Sala, A., Zachariassen, K., 2011. Improving fishing effort descriptors: modelling engine power and gear-size relations of five European trawl fleets. Fish. Res. 110, 39-46.

Eigaard, O.R., Marchal, P., Gislason, H., Rijnsdorp, A.D., 2014. Technological development and fisheries management. Rev. Fish. Sci. 22, 156-174.

Feekings, J., Bartolino, V., Madsen, N., Catchpole, T., 2012. Fishery discards: factors affecting their variability within a demersal trawl fishery. PLoS One 7 (4), e36409, http://dx.doi.org/10.1371/journal.pone.0036409, PMID:22558463.

Frandsen, R.P., Hermann, B., Madsen, N., 2010. A simulation-based attempt to quantify the morphological component of size selection of Nephrops norvegicus in trawl codends. Fish. Res. 101, 156-167.

Giampiero, M., Wood, S.N., 2011. Practical variable selection for generalized additive models. Comput. Stat. Data Anal. 55, 2372-2387.

Hillis, J.P., Earley, J.J., 1982. Selectivity in the Nephrops trawl. ICES CM 1982/B:19.

Main, J., Sangster, G.I., 1985. The Behaviour of the Norway Lobster, Nephrops Norvegicus (L.), During Trawling. Marine Laboratory, Aberdeen.

Main, J., Sangster, G.I., 1981. A study of the fish capture process in a bottom trawl by direct observations from a towed underwater vehicle. Scottish Fisheries Research Report, 23. 24 pp.

Newland, P.L., Chapman, C.J., 1989. The swimming and orientation behaviour of the Norway lobster, Nephrops norvegicus (L.), in relation to trawling. Fish. Res. $8,63-80$.

Robertson, J.H.B., Ferro, R.S.T., 1991. Selectivity of Nephrops trawls. EEC Study Contract 1991/9, final report. Aberdeen. The Scottish Office Agriculture and Fisheries Department, pp. 1-15.

Sainsbury, J.C., 1996. Commercial fishing methods, an introduction to vessels and gears. In: Fishing News Books. Blackwell Science Ltd., Oxford, pp. 359.

Sangster, G.I., Breen, M., 1998. Gear performance and catch comparison trails between a single trawl and a twin rigged gear. Fish. Res. 36, 15-26.

Thorsteinsson, G., 1986. On the behaviour of Nephrops against bottom trawls as observed with an underwater TV. ICES CM 1986/B:45.

Tweedie, M.C.K. An index which distinguishes between some important exponential families. In: J. K. Ghosh and J. Roy, (ed.), Statistics: Applications and New Directions, pages 579-604. Proceedings of the Indian Statistical Institute Golden Jubilee International Conference, Calcutta: Indian Statistical Institute, 1984.

Wardle, C.S., 1993. Fish behaviour and fishing gear. In: Pitcher, T.J. (Ed.), Behaviour of Teleost Fishes. , 2nd edn. Chapman and Hall, London, pp. 609-643.

Wood, S.N., 2011. Fast stable restricted maximum likelihood and marginal likelihood estimation of semiparametric generalized linear models. J. Roy. Stat. Soc. B. 73, 3-36 